\title{
PENGARUH PEMBINAAN DAN KOORDINASI INTERNAL ALUMNI TERHADAP EFEKTIVITAS KERJA ASMTB BANDUNG
}

\author{
Mulyaningsih \\ Universitas Garut \\ Email: mulyaningsih@uniga.ac.id
}

\begin{abstract}
Abstrak
Penelitian ini berawal dari masalah utama yaitu, efektivitas organisasi yang lebih rendah. Manusia adalah faktor utama dalam memperoleh kesuksesan organisasi untuk mencapai tujuannya. Sejalan dengan posisi alumni ASMTB dalam menentukan keberhasilan perguruan tinggi dan implementasi sumber daya manusia, ada masalah dan tantangan yang harus dihadapi. Alumni ASMTB membutuhkan pembinaan dan koordinasi internal untuk mencapai efektivitas. Ditemukan bahwa efektivitas kinerja alumni masih rendah dan dapat disimpulkan dari keberadaan alumni yang kurang peduli tentang ASMTB dan alumni yang tidak mendaftar sebagai alumni karena sampai sekarang hanya $10 \%$ lulusan yang terlibat dalam tresshold alumni. Indikator masalah muncul karena pembinaan dan koordinasi internal yang belum dilaksanakan secara optimal. Hasil penelitian menunjukkan bahwa ada efek simultan dari 47,3\% mengenai pembinaan dan koordinasi internal. Pengujian menunjukkan bahwa pengaruh parsial pada varians efektivitas pembinaan sebesar $21,2 \%$ dan variabel koordinasi internal parsial mempengaruhi efektivitas kerja yang ditentukan sebesar 24,2\%.
\end{abstract}

Kata Kunci: Pembinaan, Koordinasi, Efektivitas Kerja.

\section{Abstract}

This research is originated from the main problem that is, the lower organizational effectiveness. Human is the main factor in gaining an organization's success to achieve its objectives. In line with the position of ASMTB alumni in determining the success of the college and the implementation of human resources, there are problems and challenges that must be faced. The alumni of ASMTB require coaching and internal coordination to achieve effectiveness. It was found that the effectiveness of alumni performance is still low and it can be inferred from the existence of the alumni who are less concerned about ASMTB and the alumni who do not register as alumni because until now it is only $10 \%$ graduates were involved in the alumni tresshold. The problem indicators appear caused by internal coaching and coordination that has not been implemented optimally. The results show that there is a simultaneous effect of $47.3 \%$ regarding the internal coaching and coordination. Testing indicates that the partial effect on the variance of coaching effectiveness of $21.2 \%$ and a partial internal coordination variables influence the effectiveness of the work which is determined by $24,2 \%$.

Keyword: Coaching, Coordination, Work Effectiveness.

\section{A. PENDAHULUAN}

Suatu organisasi pada dasarnya merupakan bentuk kesatuan kerja yang terdiri dari dua orang atau lebih yang bekerja bersama tunduk pada kerangka kerja untuk 
mencapai tujuan yang dimaksud. Dalam ikatan ini terdapat seseorang atau sekelompok orang yang disebut pimpinan dan bawahan atau lembaga dengan kelompok di dalammya termasuk lulusan dari sebuah perguruan tinggi. Berdasarkan hal tersebut dapat dikatakan bahwa faktor manusia merupakan faktor utama dalam mencapai suatu keberhasilan organisasi di dalam mencapai tujuannya.

Sejalan dengan kedudukan alumni dalam menentukan keberhasilan atau kelancaran penyelenggaraan perguruan tinggi dan pelaksanaan pembangunan sumber daya manusia, maka tidak sedikit masalah dan tantangan yang harus dihadapi. Alumni ASMTB memerlukan pembinaan dan pengkoordinasian serta pengarahan secara serasi kepada Alumni guna mencapai efektivitas kerja ASMTB. Berdasarkan hal tersebut di atas dipertegas bahwa proses pembinaan dan koordinasi merupakan upaya yang dilakukan oleh ASMTB dalam mencapai efektivitas kerja ASMTB melalui pengoptimalan peran Alumni, karena pembinaan dan koordinasi mempunyai pengaruh ketika digunakan oleh pimpinan dalam menggerakkan Alumninya bagi meningkatkan efektivitas kerja dalam suatu perguruan tinggi.

Berdasarkan hasil penjajakan awal yang dilakukan pada alumni ASMTB Bandung, ditemukan indikator-indikator masalah yang menunjukkan bahwa efektivitas kerja ASMTB masih di bawah yang diinginkan, indikasinya antara lain:

1. Masih adanya alumni yang kurang peduli kepada ASMTB dalam melaksanakan tugasnya dengan baik sehingga kurang memiliki kemampuan dan berdampak kepada rendahnya kualitas pelayanan.

2. Masih adanya alumni yang tidak mendaftarkan diri sebagai alumni karena baru $10 \%$ yang terlibat dalam kegiatan alumni yang mendukung almamater dikarenakan yang bersangkutan kurangnya rasa tanggung jawab dari alumni dalam melaksanakan tugastugas sebagai alumni ASMTB.

Indikator-indikator masalah tersebut diduga disebabkan oleh pembinaan dan koordinasi internal yang belum dilaksanakan secara optimal. Berdasarkan masalah di atas, dapat dipahami bahwa faktor-faktor pembinaan dan koordinasi merupakan faktor yang mendapat perhatian dalam upaya meningkatkan efektivitas kerja organisasi di Akademi Sekretari dan Manajemen Taruna Bakti Bandung, sehingga peneliti tertarik pada penelitian yang berjudul Pengaruh Pembinaan dan Koordinasi Internal Alumni Terhadap Efektivitas Kerja Akademi Sekretari dan Manajemen Taruna Bakti (ASMTB) Bandung. 


\section{B. KERANGKA TEORITIS DAN HIPOTESIS}

\section{Pembinaan}

Manajemen IKA ASMTB atau manajemen personalia diperlukan untuk meningkatkan efisiensi dan efektifitas sumber daya manusia dalam organisasi, tujuannya adalah untuk menyediakan unit kerja yang efektif untuk organisasi. Upaya peningkatan dayaguna dan hasilguna sumber daya manusia pada organisasi dapat dilakukan dengan upaya pembinaan terhadap sumber daya manusia atau alumni dalam organisasi tersebut. Dengan adanya pelaksanaan pembinaan, diharapkan setiap sumber daya manusia atau alumni ASMTB yang berkecimpung dalam organisasi dapat memberikan kinerja terbaik, sehingga akan benar-benar memainkan peran pekerjaan yang bermanfaat dan seefektif mungkin sesuai dengan tujuan yang ingin dicapai oleh organisasi.

Adapun pengertian pembinaan menurut Hamalik (1993:121), adalah sebagai berikut: "Pembinaan merupakan kebutuhan, mengingat perkembangan ilmu pengetahuan dan teknologi, tuntutan program organisasi dan pengembangan sumber daya manusia". Atmosudirjo (1980:114), mengemukakan arti pembinaan dalam istilah-istilah Indonesia dalam manajemen, adalah: "Manajemen yang bersifat pengembangan daripada jiwa, atau kemampuan, atau keahlian seseorang, atau orang-orang, kelompok, dan sebagainya (human development management)." Dari uraian-uraian diatas, dapat ditarik kesimpulan bahwa pembinaan adalah kebutuhan pengembangan yang menyangkut pada sumber daya manusia atau alumni.

Pendapat Watkins dalam Moenir (1994:153), selanjutnya mempertegas pengertian pembinaan adalah sebagai berikut: "Pembinaan alumni adalah pembinaan terhadap pribadipribadi, masalah-masalah dan hubungannya yang berkaitan, terutama dengan masalah-masalah dan hubungan terhadap penyesuaian pribadi. Musanef (1996:17) mengemukakan pengertian pembinaan terhadap pegawai atau alumni, adalah sebagai berikut: Pembinaan pegawai merupakan upaya untuk mendapatkan pegawai dan mengembangkan profesionalisme dan keterampilan sesuai tuntutan tugas organisasi sehingga dapat menghasilkan prestasi kerja yang sebaik-baiknya guna mencapai tujuan, sasaran dan program organisasi yang telah ditetapkan.

Adapun fungsi-fungsi pembinaan, menurut Supriatna (1993:94), meliputi:
a. Pemberian bimbingan
b. Pemberian petunjuK
c. Pengaturan
d. Pengawasan 
e. Pengendalian

f. Pemantauan

g. Evaluasi

h. Pengembangan serta penentuan kebijakan."

\section{Koordinasi Internal}

Secara etimologis, istilah "koordinasi" berasal dari bahasa Latin dan terdiri dari "Cum" (artinya beragam) dan "Ordinare" (artinya pengaturan dan penempatan). Untuk meraih tujuan utama organisasi secara cepat salah satu alatnya adalah koordinasi, seperti yang diungkapkan oleh Sugandha (1991:12-13): “Koodinasi adalah penyatupaduan gerak dari seluruh potensi dan unit-unit organisasi atau organisasi-organisasi yang berbeda fungsi agar secara benar-benar mengarah pada sasaran yang sama guna memudahkan pencapaiannya dengan efisien".

Hal senada juga diungkapkan oleh Hasibuan (1997:85), bahwa koodinasi dapat diartikan menggerakkan segala usaha organisasi untuk melaksanakan usaha sebanyak mungkin atau koodinasi berarti usaha mencegah terjadinya kekacauan, percekcokan, kekembaran atau kekosongan pekerjaan. Orang-orang dan pekerjaannya diselaraskan dan diarahkan pada pencapaian tujuan tertentu. Jadi, mengkoordinasikan semua unsur-unsur manajemen $(6 \mathrm{M})$.

Jelaslah bahwa koodinasi merupakan suatu pengaturan di mana potensi serta kegiatan organisasi dapat berjalan seiring dan serasi agar setiap personal atau grup dalam organisasi dapat memahami peran masing-masing terhadap organisasi. Menurut Sugandha (1991:47- 48) mengajukan prinsip-prinsip koodinasi dibagi menjadi tujuh prinsip yaitu:

a. Adanya kesepakatan dan kesatuan pengertian mengenai sasaran yang harus dicapai sebagai arah kegiatan bersama

b. Adanya kesepakatan mengenai kegiatan atau tindakan yang harus dilakukan oleh masing-masing pihak, termasuk target dan jadwalnya.

c. Adanya ketaatan dan loyalitas dari setiap pihak terhadap bagian tugas masing-masing serta jadwal yang telah ditetapkan.

d. Adanya saling tukar informasi dari semua pihak yang saling bekerja sama mengenai kegiatan dan hasilnya pada suatu saat tertentu, termasuk masalah-masalah yang dihadapi masing-masing. 
e. Adanya koordinator yang dapat memimpin dan menggerakkan serta memonitor kerja sama tersebut, serta memimpin pemecahan masalah bersama.

f. Adanya informasi dari berbagai pihak yang mengalir kepada koodinator sehingga koodinator dapat memonitor seluruh pelaksanaan kerja sama dan mengerti masalahmasalah yang dihadapi oleh semua pihak.

g. Adanya saling hormati terhadap wewenang fungsional masing-masing pihak sehingga tercipta semangat untuk saling bantu."

Berdasarkan uraian-uraian di atas, bahwa manajemen adalah suatu proses kerja sama yang dilakukan melalui individu lain untuk mencapai tuiuan yang telah disetujui antara lain melalui adanya proses pembinaan yang mengacu pada pendapat Koontz dan O’Donnel, dalam Siagian (1999:105), Newman dalam Handayaningrat (1999:20), mengemukakan fungsi-fungsi manajemen yang mencakup fungsi directing (pemberian bimbingan); dan Fayol dalam Siagian (1999:103) serta Gullick dalam Handayaningrat (1999:24), mengemukakan fungsi-fungsi manajemen antara lain mencakup coordinating (pengkoordinasian).

\section{Efektivitas Kerja}

Efektivitas asal katanya yaitu "effective" yang artinya "berhasil, ditaati, berlaku, manjur dan mulai berlaku" dari bahasa Inggris. Kalimat efektivitas biasanya digunakan dalam berbagai target dan tujuan yang telah ditentukan terlebih dahulu atau maksud-maksud tertentu, begitu pula peraturan-peraturannya atau dasar-dasar hukumnya harus ditaati dari mulai berlakunya peraturan-peraturan tersebut. Efektivitas kerja berarti pengukuran dalam arti tercapainya sasaran atau tujuan yang telah ditentukan sebelumnya (Handayaningrat, 1998:16).

Tolok ukur daripada efektivitas kerja menurut Umar (1998:261), yaitu:

a. Mutu Pekerjaan

b. Kejujuran Karyawan

c. Inisiatif

d. Kehadiran

e. Sikap

f. Pengetahuan tentang pekerjaan

g. Tanggung jawab

h. Pemanfaatan waktu.

Menurut Emerson (dalam Handayaningrat, 1990:16), efektivitas adalah pengukuran dalam arti tercapainya sasaran dan tujuan yang telah ditentukan sebelumnya. Dari pendapat- 
pendapat tersebut dapat diambil intinya bahwa yang dimaksud efektivitas kerja ASMTB adalah suatu kondisi dimana hasil kerja yang dicapai seorang IKA ASMTB dalam menjalankan kewajiban yang dipercayakan kepadanya bahkan bisa juga disebut sebagai output yang peroleh dari fungsi dalam jangka waktu tertentu.

Berdasarkan landasan teori di atas, diperoleh suatu kerangka kerja yang menyatakan hubungan antarvariabel yang akan diteliti sebagai berikut:

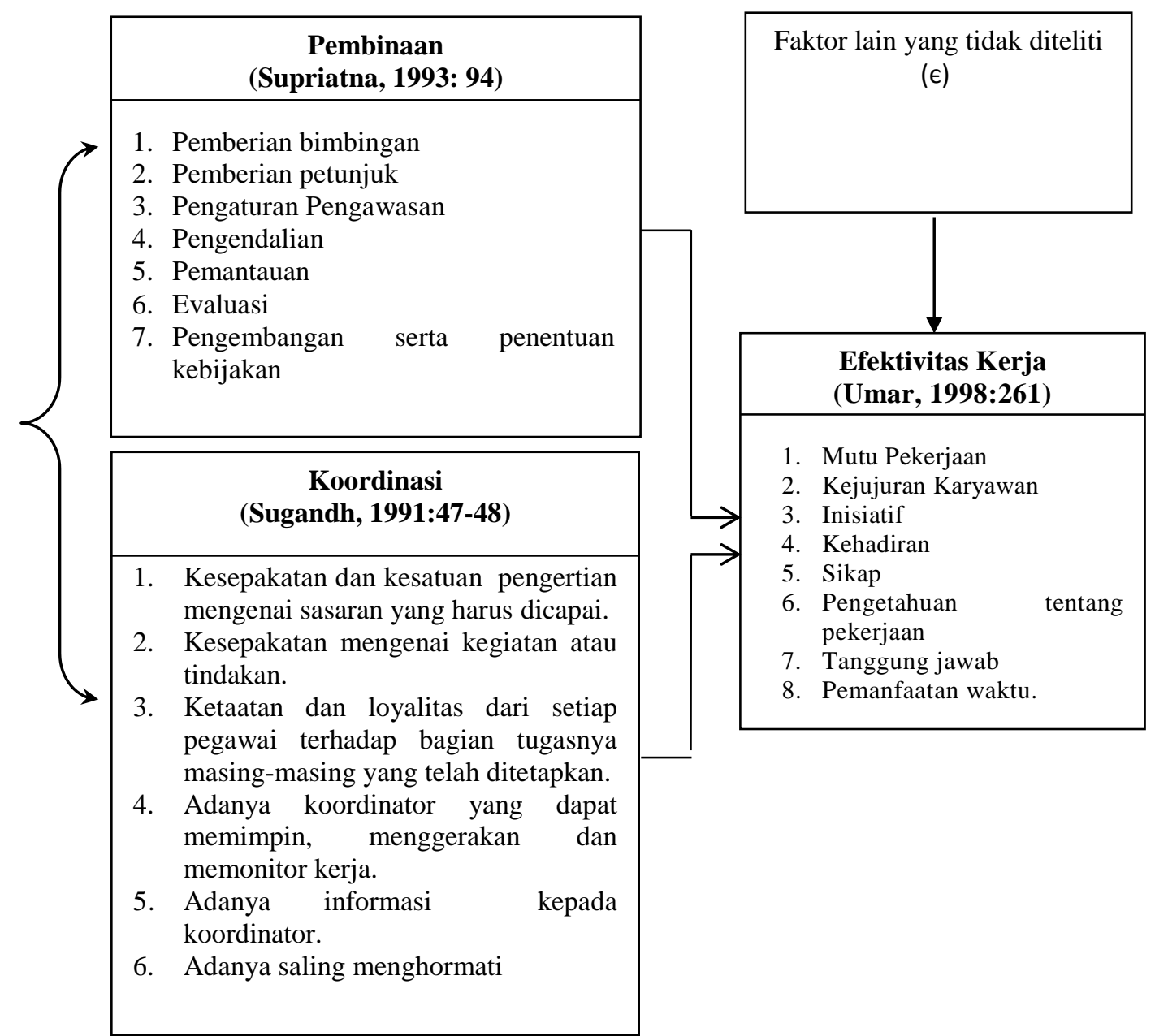

Sumber: Supriatna (1993:94), Sugandha (1991:47-48), Umar (1998:261)

\section{Gambar 1 Kerangka Pemikiran}

\section{METODE}

Metode yang digunakan adalah metode survai eksplanatori, tujuannya adalah menguji hubungan antara dua variabel atau lebih. Dalam hal ini Pembinaan dan sebagai variabel bebas $\left(\mathrm{X}_{1}\right.$ dan $\left.\mathrm{X}_{2}\right)$ berpengaruh terhadap efektivitas kerja organisasi sebagai variabel terikat $(\mathrm{Y})$. Menurut Surakhmad (1994:33), metode ekplanatoris adalah suatu penelitian yang mempunyai tujuan untuk menguji hipotesis yang menyatakan hubungan sebab akibat antara dua variabel 
atau lebih dengan bias yang kecil dan meningkatkan kepercayaan. Jenis penelitian yang dipergunakan dalam penelitian ini adalah survey deskriptif. Menurut Singarimbun dan Efendi (1995:63), pengertian survey deskriptif yaitu uatu kegiatan penelitian yang meneliti status kelompok manusia, suatu objek, suatu kondisi, suatu sistem pemikiran atau suatu kelas peristiwa pada masa sekarang.

Mengingat banyaknya populasi yang dijadikan objek penelitian, maka penulis melakukan penelitian pada sebagian dari objek tersebut yang dianggap mewakili dari keseluruhan objek yang disebut teknik sampel. Teknik sampel yang digunakan yaitu Proportionate Stratified Random Sampling, yaitu pengambilan sampel dari anggota populasi secara acak dan berstrata secara proporsional, dilakukan sampling ini apabila anggota populasinya heterogen (tidak sejenis) (Akdon, 2005:100).

Pengumpulan data yang diperlukan untuk penelitian ini adalah data primer dan sekunder. Data primer diperoleh dari hasil penelitian secara empirik melalui penyebaran angket kepada responden dengan tujuan untuk mengetahui persepsi mereka mengenai pembinaan dan koordinasi internal alumni terhadap efektivitas kerja di ASMTB Bandung. Sedangkan data sekunder diperoleh dari hasil wawancara yang dilakukan pada beberapa objek sampel penelitian yang meliputi masyarakat, Dunia Industri dan alumni. Untuk mengetahui keabsahan dari angket digunakan uji validitas dan realibitas terhadap angket.

Uji validitas digunakan untuk mengetahui tepat tidaknya angket yang tersebar. Adapun alat yang digunakan adalah Korelasi Product Moment dari Pearson, sebagai berikut:

$$
r_{x y}=\frac{n \sum X Y-\left(\sum X\right)\left(\sum Y\right)}{\sqrt{\left\{n \sum X^{2}-\left(\sum X\right)^{2}\right\}\left\{n \sum Y-\left(\sum Y\right)^{2}\right\}}}
$$

Keterangan:

$\mathrm{r}_{\mathrm{xy}}$ : Koefisien korelasi

$\mathrm{n}$ : Banyaknya sampel yang di teliti

$\mathrm{X} 1$ : Nilai variabel independen yaitu pembinaan

$\mathrm{X} 2$ : Nilai variabel independen yaitu koordinasi internal

Y : Nilai variabel independen efektivitas kerja ASMTB (Sugiyono, 2000:148)

Untuk dapat memenuhi instrumen penelitian yang sifatnya selalu dapat dipercaya (reliabel), maka digunakan uji reliabilitas untuk mengetahui ketepatan nilai angket, artinya instrumen penelitian reliabel bila diujikan pada kelompok yang sama walaupun pada waktu yang berbeda hasilnya akan sama. Pengujian reliabilitas ini menggunakan Alpha, yaitu:

$$
\alpha=\frac{\mathrm{kr}}{1+(\mathrm{k}-1) \mathrm{r}}
$$


Keterangan:

$\mathrm{r}$ : rata-rata korelasi antarvariabel manifes

$\mathrm{k}$ : jumlah variabel manifes yang membentuk variabel laten

$\alpha$ : nilai keandalan

Analisis data yang digunakan untuk mengungkapkan pengaruh pembinaan dan koordinasi internal alumni terhadap efektivitas kerja ASMTB mengggunakan analisis jalur (path analysis). Karena tingkat pengukuran skala kuesioner teratur, pertama-tama harus diproses lebih lanjut menjadi skala interval menggunakan metode successive interval (MSI). Dengan Populasi dalam penelitian ini adalah alumni di seluruh Indonesia yang berjumlah 100 orang dari Luar Pulau Jawa, Pulau Jawa, Jawa Barat, Bandung, dan Kabupaten Bandung.

\section{HASIL DAN PEMBAHASAN}

Efektivitas kerja adalah masalah penting dalam kegiatan administrasi karena dapat digunakan sebagai umpan balik bagi manajer dan pembuat keputusan Menurut Emerson (dalam Handayaningrat, 1990:16), efektivitas adalah ukuran apakah tujuan yang telah ditentukan telah tercapai. Efektivitas kerja ASMTB perlu dikembangkan sebagai tolok ukur untuk membandingkan pekerjaan yang telah selesai dengan pekerjaan yang diharapkan terkait dengan bimbingan alumni dan koordinasi internal. Standar-standar ini juga dapat digunakan untuk mengukur tanggung jawab atas apa yang dilakukan.

Tolok ukur efektivitas kerja menurut Umar (1998:261) yaitu sebagai berikut:

1. Mutu Pekerjaan

2. Kejujuran Karyawan

3. Inisiatif

4. Kehadiran

5. Sikap

6. Pengetahuan tentang pekerjaan

7. Tanggung jawab

8. Pemanfaatan waktu.

Berdasarkan hasil perhitungan dengan menggunakan analisa jalur (path analyisis) dapat dilihat bahwa pembinaan dan koordinasi internal terhadap efektivitas kerja ASMTB, dengan besar koefisien determinasi untuk semua variabel pengaruhnya 25,6\%.dan pengaruh secara simultan pembinaan dan koordinasi internal terhadap efektivitas kerja ASMTB 47,3\% serta $52,7 \%$ di luar yang belum diteliti. 
Secara parsial, variabel pembinaan melalui pemberian bimbingan 79\% sangat baik, pemberian petunjuk 39\% sedang, pengaturan 55\% setuju bahkan $25 \%$ sangat setuju sangat baik, pengawasan $73 \%$ ditetapkan $41 \%$ sedang, pengendalian $40 \%$ katagori sedang, pemantauan 50\% sedang, evaluasi 58\%,pengembangan serta penentuan kebijakan $72 \%$ sangat baik berpengaruh terhadap efektivitas kerja asmtb sebesar $21,2 \%$.

Hasil pengujian pada variabel secara parsial, kesepakatan dan kesatuan pengertian mengenai sasaran yang harus dicapai adalah $60 \%$ setuju kategori baik; kesepakatan mengenai kegiatan atau tindakan 55\%, kategori baik; ketaatan dan loyalitas dari setiap alumni terhadap bagian tugasnya masing-masing yang telah ditetapkan 35\%, kategori sedang, dan kegiatan berdasarkan pada pedoman kerja 52\%, adanya koordinator yang dapat memimpin, menggerakkan dan memonitor kerja 38\% setuju katagori sedang dan kesesuaian kegiatan dengan bagian/ beban tugas yang diberikan adalah $40 \%$ setuju katagori sedang, adanya informasi kepada koordinator $77 \%$, dan hasil kegiatan masing-masing alumni dilaporkan kepada pimpinan asmtb $62 \%$ setuju katagori baik, dimensi informasi; Informasi Koordinator dalam penyampaian informasi merupakan bagian dari variabel koordinasi internal adalah $45 \%$ setuju dan $60 \%$ setuju katagori baik sangat berpengaruh terhadap efektivitas kerja $24,2 \%$. Dengan masih adanya alumni yang tidak mendaftarkan diri sebagai alumni karena baru $10 \%$ yang terlibat dalam kegiatan alumni. Dengan demikian, semakin tepat pembinaan dan koordinasi internal terhadap efektivitas kerja ASMTB dan semakin optimal pembinaan dan koordinasi internal alumni, maka semakin optimal efektivitas kerja ASMTB.

\section{E. KESIMPULAN}

Hasil penelitian menunjukkan bahwa secara simultan menunjukkan ada pengaruh sebesar 47,3\%. Pengujian secara parsial mengindikasikan bahwa variansi pembinaan berpengaruh terhadap efektivitas kerja ASMTB sebesar 21,2\%. Secara parsial variabel koordinasi internal ditentukan berpengaruh terhadap efektivitas kerja sebesar 24,2\%.

\section{DAFTAR PUSTAKA}

Handayaningrat, S. (1999). Pengantar Ilmu Administrasi dan Manajemen. Jakarta: Gunung Agung.

Hasibuan, M. S. P. (1996). Manajemen Dasar, Pengertian dan Masalah. Jakarta: Gunung Agung. 
Manullang. (1992). Manajemen Personalia. Jakarta: Ghalia Indonesia.

Moenir. (1994). Pendekatan Manusiawi dan Organisasi Terhadap Pembinaan Kepegawaian. Jakarta: Haji Masagung

Nitisemito, A. S. (1996). Manajemen Personalia (Manajemen Sumber Daya Manusia). Jakarta: Ghalia, Indonesia

Rusidi. (2001). Menyusun Usulan Penelitian. Bandung: Program Pascasarjana Universitas Padjadjaran

Siagian, S. P. (1999). Organisasi, Kepemimpinan dan Perilaku Administrasi. Jakarta: Toko Gunung Agung.

Silalahi, U. 1999. Metode dan Metodologi Penelitian. Bandung: Bina Budhaya.

Sugiyono. (2004). Metode Penelitian Administrasi. Bandung: Alfabeta.

Sitepu, N. (1994). Analisis Jalur (Path Analysis). Bandung: Unit Pelayanan Statistika FMIPA Universitas Padjadjaran.

Sudriamunawar, H. (2002). Pengantar Studi Administrasi Pembangunan. Bandung: Mandar Maju.

Sugandha, D. (1991). Koordinasi Alat Pemersatu Gerak Administrasi. Jakarta: Intermedia.

Supriatna, T. (1993). Sistem Administrasi Pemerintahan Daerah. Jakarta: Bumi Aksara.

Umar, H. (1995). Manajemen Sumber Daya Manusia. Buku Panduan Mahasiswa. Jakarta: Gramedia Pustaka Utama. 